\title{
ROLE OF TRANSCUTANEOUS ELECTRICAL NERVE STIMULATION (TENS) IN MANAGEMENT OF PAIN IN OSTEOARTHRITIS (OA) OF KNEE
}

\author{
KHAN MH ${ }^{1}$, RAHMAN $\mathrm{S}^{2}$, HOSSAIN $\mathrm{S}^{3}$, HOSSAIN MM ${ }^{4}$, KHATUN M ${ }^{5}$, KAMAL AHMM ${ }^{6}$, \\ AHMED $\mathrm{M}^{7}$, PARVEEN $\mathrm{S}^{8}$, NAZNEEN $\mathrm{S}^{9}$, SAHA $\mathrm{K}^{10}$
}

\begin{abstract}
Context: Osteoarthritis is primarily a disease of cartilage as it is characterized by the degradation of hyaline cartilage in the joints. It is believed to be a dynamic disease that reflects the balance between destruction and repair. Clinically, there is pain, swelling of joints and limitation of motion. Pathological disease is characterized by focal erosive lesions, cartilage destruction, subchondral sclerosis, cyst formation and large osteophyte at the margin of the joints. The objectives of management of osteoarthritis (OA) of the knee are to relieve pain, maintain or improve mobility, and minimize disability. Treatment options include non -pharmacologic intervention, drug therapy, and surgery. Different modalities of physical therapy have been shown to help improve clinical symptoms and function of knee OA with fewer adverse effects. Transcutaneous electrical nerve stimulation (TENS) is among these non invasive therapies which have been used to treat a variety of painful acute and chronic conditions including osteoarthritis.

Material and Methods: This randomized clinical trial was conducted on 60 (sixty) patients attending in Physical Medicine and Rehabilitation department of Dhaka Medical College Hospital, who were suffering from knee osteoarthritis. The patients were randomly divided into two groups, Group-A and Group-B. The patients were evaluated clinically and data was collected from both groups in a pre designed data collection sheet for visual analogue scale (VAS) on Pain, 50 feet walking time in seconds and tenderness index in every two weeks interval from the first visit for up to 6 weeks. All the data were analyzed by SPSS version 16.1.

Result : The present study showed pain, tenderness and walking time were significantly improved in Group A who were treated with TENS, NSAID \& ADL instructions than in Group $B$ who were treated with NSAID \& ADL instructions after 6 weeks $(P<0.05)$.

Conclusion: The results of this study suggest that application of TENS along with NSAIDs and $A D L$ instructions is more effective in reduction of pain and improving functional performances in patients with knee osteoarthritis than the drug only treatment.
\end{abstract}

Key words: TENS, pain management, osteoarthritis.

J Dhaka Med Coll. 2018; 27(1) : 62-67

\section{Introduction}

Osteoarthritis $(\mathrm{OA})$ is the most common form of arthritis and one of the most important causes of long term disability in adults ${ }^{1}$.
Osteoarthritis has a worldwide distribution though there is a variation in the prevalence among different ethnic groups and genders. OA mainly affects the elderly population. The

1. Dr. Moinuddin Hossain Khan, Assistant Professor, Physical Medicine, National Institute of Traumatology and Orthopedic Rehabilitation (NITOR), Dhaka.

2. Prof. Dr. Sohely Rahman, Professor and Head, Department of Physical Medicine and Rehabilitation, Dhaka Medical College Hospital, Dhaka.

3. Dr. Md. Shahadat Hossain, Associate Professor and Head, Department of Physical Medicine and Rehabilitation, Shaheed Suhrawardy Medical College, Dhaka

4. Dr. Muhammad Mahbub Hossain, Junior Consultant, Medicine, 300 Bedded Hospital, Khanpura Narayangonj

5. Dr. Maksuda Khatun, Junior Consultant,Medicine, Upazilla Health Complex, Sreepur, Gazipur.

6. Dr. A.H.M. Mostafa Kamal, Associate Professor, Department of Anatomy. Dhaka Medical College,Dhaka.

7. Dr. Monzur Ahmed, Assistant Professor, Physical Medicine and Rehabilitation, Shaheed Suhrawardy Medical College, and Hospital, Dhaka

8. Dr. Sanjida Pervin, Assistant Professor, Physical Medicine, National Institute of Diseases of Chest and Hospital, Dhaka

9. Dr. Suraiya Nazneen, Registrar, Critical Care Medicine, BIRDEM, Dhaka

10. Dr. Kanol Saha, Associate Professor, Department of Neuromedicine, Dhaka Medical College, Dhaka

Correspondence: Dr. Moinuddin Hossain Khan, Assistant Professor, Physical Medicine, National Institute of Traumatology and Orthopedic Rehabilitation ( NITOR), Dhaka, Phone- +8801712771353, E-mail- moinuddin_h_khan@yahoo.com

Received: 21 July $2017 \quad$ Revision: 01 September 2017

DOI: http://dx.doi.org/10.3329/jdmc.v27i1.38948

Accepted: 15 September 2017 
prevalence of OA in population older than 60 years of age is more than $50 \%{ }^{2}$. Common sites of joints to develop OA include the knee, hand, hip, spine and foot. Of these, OA of the knee is most commonly found. In addition to increasing age, OA knee is associated with obesity, trauma, history of inflammatory arthritis, and certain metabolic diseases such as acromegaly and calcium pyrophosphate dihydrate (CPPD) arthropathy ${ }^{3}$.

Men and women are equally likely to develop OA, but more joints are affected in women than in men. Osteoarthritis is much more common in some joints (the fingers, hip, knee and spine) than in others (the elbow, wrist and ankle). The knee and hip are the principal large joints involved, affecting $10-25 \%$ of those aged over 65 years $^{4}$.

The objectives of management of $\mathrm{OA}$ of the knee are to relieve pain, maintain or improve mobility, and minimize disability. Treatment options include non-pharmacologic intervention, drug therapy and surgery. In 1995, the American College of Rheumatology (ACR) published guidelines for the treatment of OA knee ${ }^{5}$. These were updated in 2000 (ACR 2000), 2003 (ACR 2003) and 2012 stating that, for mild symptomatic OA, treatment may include non-pharmacologic methods (patient education, physical and occupational therapy and other therapies) and pharmacologic therapy including non- opoid oral and topical (i.e., applied to skin) analgesics ${ }^{6}$. For patients who are unresponsive to this regimen, the use of non-steroidal anti-inflammatory drugs (NSAIDs) is considered appropriate. Corticosteroid injection is recommended for patients with knee OA, particularly when signs of local inflammation with joint effusion are present ${ }^{7}$. Patients with severe symptom of OA of the knee may require surgical intervention e.g. Osteotomy or total joint arthroplasty. Autologous Chondrocyte Implantation may be a possible treatment. Clinical trials employing tissue engineering methods have demonstrated regeneration of cartilage in damaged knees, including those that had progressed to osteoarthritis $^{8}$.
Different modalities in physical therapy have been shown to help improve clinical symptoms and function of knee OA with fewer adverse effects than medical treatment. Transcutaneous electrical nerve stimulation (TENS) is among these non-invasive therapies which have been used to treat a variety of painful acute and chronic conditions ${ }^{9}$.The benefits of TENS for relieving chronic pain are well documented ${ }^{10}$. This neuromodulatory method is based on the 'Gate-Control Theory of pain perception as described by Melzack and Wall ${ }^{11}$.Pain impulses are transmitted to the spinal cord via small cutaneous (delta) fibers. TENS stimulates large cutaneous (beta) fibers that subsequently transmit a faster impulse via $\mathrm{C}$-fibers to inhibit the pain signals from the small fibers. Thus, TENS devices were designed to be used as afferent nerve stimulators that provide adequate pain relief without involving invasive procedures. TENS may also stimulate endogenous opiates secretion ${ }^{12}$.

\section{Materials and Methods:}

The present study was performed on 60(sixty) patients (who fulfilled the selection criteria) suffering from osteoarthritis attending in the Physical Medicine and Rehabilitation department of Dhaka Medical College Hospital, Dhaka during the period of six months from March to August of 2013. The patients were divided into two groups (Group-A and GroupB). Each group consisted of 30 patients. The pre-designed semi-structured questionnaire was used for all cases. Assessments included clinical findings, OA knee characteristics, impairments and functional abilities. Group A patients received TENS (Frequency $80 \mathrm{~Hz}$, intensity $10-30 \mathrm{~mA}$, electrodes placed over the painful area of knee region with intensity in the tactile sensation threshold, 3 days in a week, 20 minutes on each day,) along with NSAID (Tab. Aceclofenac-100 mg \& Cap.Omeprazole$20 \mathrm{mg}$ twice daily) \& Activities of Daily Living (ADL) instructions for a period of 6 weeks. Group B received NSAID (Tab. Aceclofenac-100 mg \& Cap.Omeprazole-20 mg twice daily) \& ADL instructions for the same duration. Data was collected from both group-A and group-B in a pre designed data collection sheet from the first visit. Further data was collected from each 
patient in every two weeks interval from the first visit for up to 6 weeks. Methods of assessment were Visual analogue scale (VAS) for pain, 50 feet walking time in seconds and Tenderness index. All the data were analyzed by SPSS version 16.1 .

\section{Operational definitions:}

TENS: TENS (Transcutaneous Electrical Nerve Stimulation) is a noninvasive modality of physical therapy which is used in painful acute and chronic condition. Four types of TENS device settings are currently used in clinical practice $^{13}$. In this study, high frequency $(80 \mathrm{~Hz})$ TENS with $10-30 \mathrm{~mA}$ intensity in the tactile sensation threshold was used.

ADL : Activities of Daily Living encompass activities required for personal care, including feeding, dressing, grooming, bathing and toileting. ${ }^{14}$

\section{Visual analogue scale (VAS) :}

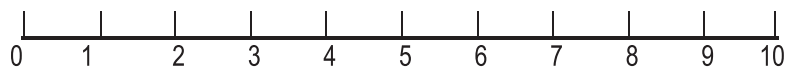

In VAS, patient (he/she) describes the visual impression of his/her pain, Zero means no pain at all and 10 means extreme pain as it is not tolerable by the patient. On the other hand 5 mean medium pain and can be tolerated by the patient. Thus they point out the actual point of pain in the scale and it was documented in the data sheet ${ }^{15}$.

\section{0 feet walking time in seconds:}

How many seconds a patient has to spend to cross 50 feet distance ${ }^{16}$.

Tenderness Index ${ }^{17}$ :

$0=$ No pain

$1=$ Describes pain

$2=$ Patient winches

$3=$ Patient winches and withdraw the affected part

$4=$ the patient will not allow the joint to be touched

\section{Ethical Measures:}

All participants were volunteered. Informed written consent was taken from the participants or parties after explaining in Bengali in details about the facts in case of primary data collection.

\section{Results:}

The present study showed the mean patient's assessment of pain on a $0-10$ visual analogue scale (VAS)was $7.40 \pm .621$ in Group A and $7.03 \pm .890$ in Group B on their respective treatment modalities. Pain scores on VAS scale after 2, 4 and 6 weeks showed progressive improvement on both group A and B. However, statistically highly significant $(p<0.005)$ improvement was observed at 4thand 6thweek of management among patient of Group A, who received TENS along with NSAID and followed ADL instructions (Table-I, Fig-1).

The mean of 50 feet walking time at 0 weeks were $19.2 \pm 1.095$ and $19.5 \pm 1.253$ among group A and B, respectively (Table-II, Fig-2). The Walking times were gradually improved in both groups in course of their respective treatment, however, significant improvement ( $\mathrm{p}$ $<0.001$ ) was recorded among group A patients who received TENS in addition to their conventional drug treatment and ADL instructions.

Tenderness index was $2.70 \pm 0.466$ in group A and $2.63 \pm 0.556$ in group $B$ at their pre treatment observations. Tenderness indexes were improved significantly $(\mathrm{p}<0.05)$ in their first follow up at the end of $2^{\text {nd }}$ week. However, the differences between groups were highly significant $(\mathrm{p}<0.001)$ at their $4^{\text {th }}$ and $6^{\text {th }}$ weeks follow ups (Table-III, Fig-3).

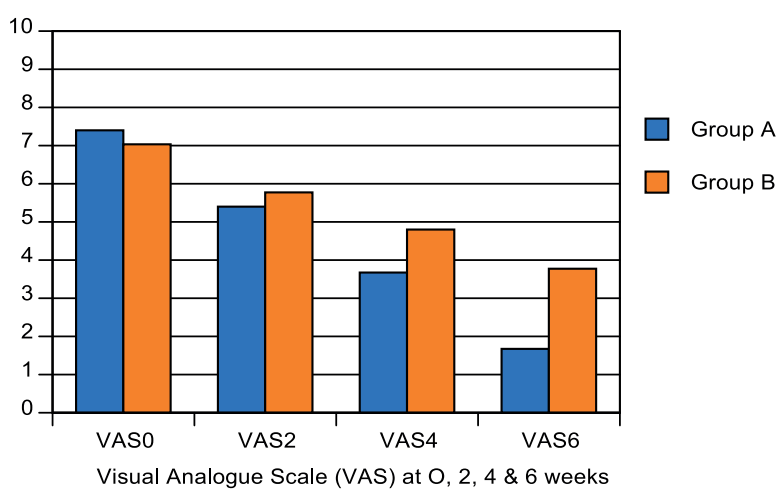

Fig.-1 : Comparison of VAS values before treatment, after 2, 4 and 6 weeks between group $A$ and $B$. 
Table -I

VAS on pain before treatment, after 2, 4 and 6 weeks.

\begin{tabular}{|c|c|c|c|c|}
\hline & Group & $\mathrm{N}$ & Mean \pm SD & $\mathrm{P}$ value \\
\hline \multirow[t]{2}{*}{ VAS 0 (pre treatment) } & A & 30 & $7.40 \pm 0.621$ & 0.07 \\
\hline & B & 30 & $7.03 \pm 0.890$ & \\
\hline \multirow[t]{2}{*}{ VAS 2 (after $2^{\text {nd }}$ week) } & A & 30 & $5.40 \pm 0.724$ & 0.09 \\
\hline & B & 30 & $5.77 \pm 0.898$ & \\
\hline \multirow[t]{2}{*}{ VAS 4 (after $4^{\text {th }}$ week) } & A & 30 & $3.67 \pm 0.844$ & $0.000^{*}$ \\
\hline & B & 30 & $4.80 \pm 0.925$ & \\
\hline \multirow[t]{2}{*}{ VAS 6(after $6^{\text {th }}$ week) } & A & 30 & $1.67 \pm 0.922$ & $0.000^{*}$ \\
\hline & B & 30 & $3.77 \pm 1.006$ & \\
\hline
\end{tabular}

* Highly significant difference between two groups at 4 and 6 weeks (t-test)

Table- II

50 feet walking time in seconds before treatment, after 2, 4 and 6 weeks.

\begin{tabular}{lcccc}
\hline & Group & N & Mean \pm SD & P value \\
\hline 50 feet walking time at 0 week & A & 30 & $19.20 \pm 1.095$ & 0.328 \\
50 feet walking time at 2 week & B & 30 & $19.50 \pm 1.253$ & \\
& A & 30 & $18.32 \pm 1.087$ & $0.003^{*}$ \\
50 feet walking time at 4 week & B & 30 & $19.23 \pm 1.194$ & \\
50 feet walking time at 6 week & A & 30 & $17.30 \pm 1.022$ & $0.000^{*}$ \\
& B & 30 & $18.53 \pm 1.042$ & \\
& A & 30 & $16.77 \pm 0.679$ & $0.000^{*}$ \\
\hline
\end{tabular}

* Highly significant between groups at 2, 4 and 6 weeks (t-test)

Table- III

Tenderness Index at different time points.

\begin{tabular}{|c|c|c|c|c|c|}
\hline & Group & $\mathrm{N}$ & Mean & Std. Deviation & $\mathrm{P}$ value \\
\hline \multirow[t]{2}{*}{ Tenderness index(pre treatment) } & $\mathrm{A}$ & 30 & 2.70 & 0.466 & 0.62 \\
\hline & $\mathrm{B}$ & 30 & 2.63 & 0.556 & \\
\hline \multirow[t]{2}{*}{ Tenderness index(after $2^{\text {nd }}$ week) } & A & 30 & 1.37 & .490 & $0.008^{*}$ \\
\hline & $\mathrm{B}$ & 30 & 1.77 & .626 & \\
\hline \multirow[t]{2}{*}{ Tenderness index (after $4^{\text {th }}$ week) } & A & 30 & .80 & .484 & $0.000 * *$ \\
\hline & B & 30 & 1.47 & .571 & \\
\hline \multirow[t]{2}{*}{ Tenderness index (after $6^{\text {th }}$ week) } & A & 30 & .13 & .346 & $0.000 * *$ \\
\hline & B & 30 & .90 & .403 & \\
\hline
\end{tabular}

Significant difference at 2 weeks and highly significant difference at 4 and 6 weeks (t-test) was seen $(\mathrm{P}<0.001)$. 


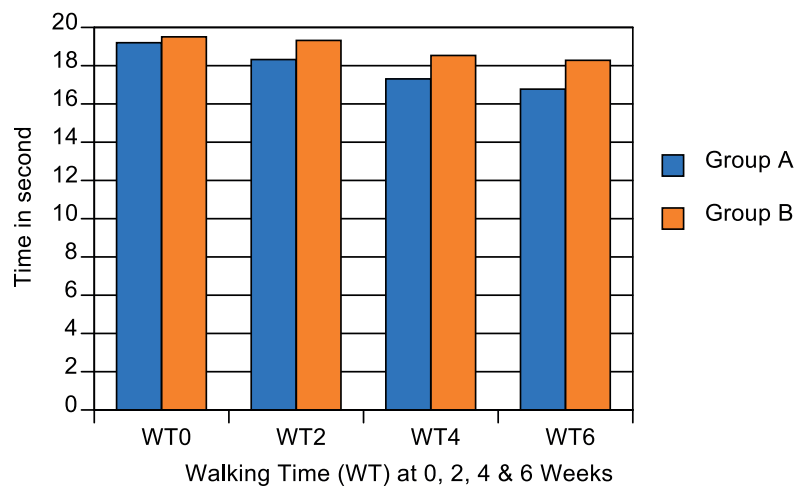

Fig.-2 : Comparison of 50 feet walking time in seconds between group $A$ and $B$.

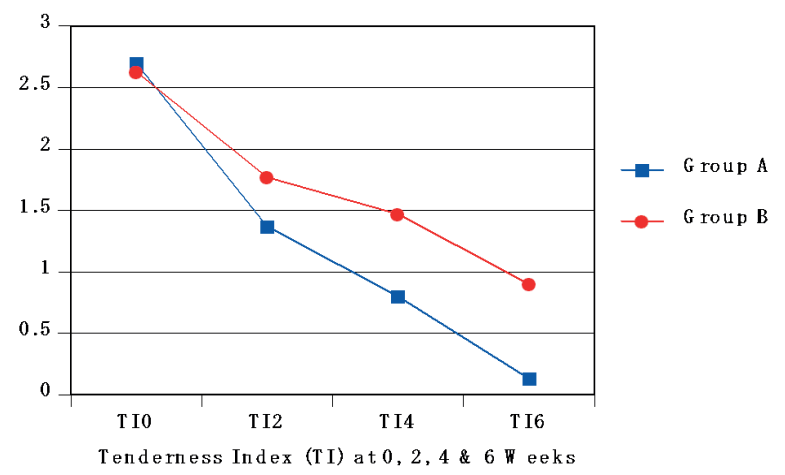

Fig-3 : Line graph of distribution of study patients according to tenderness index

\section{DIscussion:}

This randomized clinical trial was conducted on 60 patients attending in the department of Physical Medicine, Dhaka Medical College Hospital, who were suffering from Knee OA during the period of six months from March to August of 2013. The aim of this study was to evaluate the effect of TENS on reduction of pain and improvement of functional performance in patients with knee OA. At the end of treatment, we found a significant recovery in VAS on Pain, 50 feet walking time in second and Tenderness index in both groups.

Patient's assessment of pain on VAS scale was $7.40 \pm .621$ and $7.03 \pm .890$ in group A and B, respectively $(\mathrm{P}=0.07)$ on pre treatment. At the end of $2^{\text {nd }}$ week, VAS scale was $5.40 \pm .724$ and $5.77 \pm .898$ in group A and B respectively $(\mathrm{P}=0.09)$. After $4^{\text {th }}$ week, significant improvement was observed between the groups $(\mathrm{P}<0.001)$. The trends of improvements were continued throughout the whole period of six weeks of the study. At the end of $6^{\text {th }}$ week, significant improvement of symptoms of both the groups was found (Table-I, Fig1). However, the improvement among group $A$ patients is significantly higher than that of group $\mathrm{B}$ patients $(\mathrm{P}<0.001)$. Altay et al in their study also observed a significant improvement in the VAS pain scores after 3 weeks of treatment $(\mathrm{p}<0.001)$ in his both study groups. ${ }^{18}$ However, very similar to our study, the active TENS group had a greater improvement at the end of treatment when compared to the control group ( $\mathrm{p}<0.001)$. In 2012, Atamaz FC et al in their multi center double blind RCT compared the effectiveness of TENS, IFC and SWD against each other and sham intervention with exercise training and education ${ }^{19}$. They found a significant decrease in pain assessment on VAS scale $(\mathrm{P}<0.05)$ when compared with the sham groups at 3 months. The present study strongly correlates with the above mentioned studies in the other parts of the world. Table-II shows that 50 feet walking time was $19.2 \pm$ $1.095 \mathrm{sec}$ in group A and 19.50 \pm 1.253 in group B on pretreatment (Figure-II). Walking time gradually improved on subsequent follow ups after 2nd, 4thand 6thweek in group A patients who was given TENS + NSAID + ADL instruction than group $B$ who received NSAID+ ADL instruction only and it was statistically significant $(\mathrm{P}<0.005)$. Altay $\mathrm{F}$ et al in 2010 also found significant increase in functional performance parameters in 6 minutes walking test at the end 3 weeks of treatment $(p<0.001)$ with TENS and exercise in their study patients with OA knee ${ }^{18}$. Our study result was similar to their benefits in decreasing walking time. Pain is one of the major factors hindering movement. As the pain subsides, patients may become more willing to move their knees. Therefore, a significantly shorter amount of time was required to walk 50 feet distance after repeated applications of TENS.

In the present study tenderness index was 2.70 \pm .466 in group A and $2.63 \pm .556$ in group B on pre treatment period (Table-3). After $2^{\text {nd }}$ week it was $1.37 \pm .490$ and $1.77 \pm .626$ in group $A$ and $\mathrm{B}$ respectively, then $0.80 \pm .484$ and $1.47 \pm$ .571 after $4^{\text {th }}$ and $0.13 \pm .346$ and $0.90 \pm .403$ 
after $6^{\text {th }}$ week $($ Fig-3). Significant difference after $2^{\text {nd }}$ week $(\mathrm{P}=0.008)$ and highly significant difference after $4^{\text {th }}$ and $6^{\text {th }}$ week was seen $(\mathrm{P}=0.000)$ between group A(TENS + NSAID + ADL instruction) and group B(NSAID+ ADL instruction ). Pearl Law and Gladys Cheing in their study in 2004, found significant improvement on tenderness index after 2 weeks of TENS application of different frequency on people suffering from OA knee ${ }^{20}$. This study shows similar results to our study regarding tenderness.

Currently, studies showing the effects of physical therapy modalities on reduction of pain of knee OA in our country are limited. Despite this, physical therapy modalities are widely preferred for the treatment of patients at early stages of OA or advanced cases not suitable for surgery. The result of our study showed that addition of TENS to NSAID and ADL instruction in patients with knee $\mathrm{OA}$ is superior to NSAID+ ADL instruction in improving pain and functional performance.

\section{Conclusion:}

Osteoarthritis of knee is one of the most common causes of pain and disability in older people. Patients with OA knee should be treated effectively so that they can live a pain free life with improved mobility and minimum disability. The results of this study suggest that application of TENS along with NSAIDs and ADL instructions is more effective in reduction of pain and improving functional performances in patients with knee OA than the drug only treatment.

\section{References :}

1. Peyron JG, Altman RD. The epidemiology of Osteoarthritis. In: Moskowitz RW, Howell D S, Goldberg V M, Mankin H J editor(s), Osteoarthritis: Diagnosis and Management. Philadelphia: WB Saunders, 1992: 15-38.

2. Osiri M, Welch V, Brosseau L, Shea B, McGowan J, Tugwell P, Wells GA. Transcutaneous electrical nerve stimulation for Knee Osteoarthritis (Review). The Cochrane Collaboration. Published by John Wiley \& Sons Ltd, 2008; 1:2-8.

3. Fife R S Osteoarthritis: A. Epidemiology, pathology and pathogenesis. In: Klippel $\mathrm{J}$ editor(s). Primer on the rheumatic diseases. $11^{\text {th }}$ Edition. Atlanta: Arthritis Foundation, 1997:216-8.

4. M. Doherty, S.H. Ralston. Davidson s Principles and Practice of Medicine, 21st Edition, page-1083

5. Hochberg MC, Altman RD, Brandt KD, Clark BM, Dieppe PA, Griffin MR, Moskowitz RW, Schnitzer TJ:
Guidelines for the medical management of osteoarthritis. Part I. Arthritis Rheum 38:1535-1540, 1995

6. Marc C. Hochberg et al. "Recommendations for the use of Nonpharmacologic and Pharmacologic Therapies in OA of Hand, Hip and Knee" American College of Rheumatology 2012.

7. Bellamy N, Campbell J, Robinson V, Gee T, Bourne R, Wells G. Intraarticular corticosteroid for treatment of osteoarthritis of the knee (Review), The Cochrane Collaboration. Published by John Wiley \& Sons, Ltd.2007; 3:2-7.

8. Hollander AP, Dickinson SC,Sims TJ, et al (2006). "Maturation of tissue engineering cartilage implanted in injured and Osteoarthritic human knees". Tissu Eng. 12(7):1787-98.

9. Puett DW, Griffin MR. Published trials of nonmedicinal and noninvasive therapies for hip and knee osteoarthritis. Ann Intern Med 1994; 121:133-40.

10. Philadelphia Panel. Evidence-based clinical practice guidelines on selected rehabilitation interventions for knee pain. Phys Ther 2001; 81: 1675-1700.

11. Melzack R, Wall P. Pain mechanisms: A new theory. Science 1965; 150:971-7.

12. Grimmer K. A controlled double blind study comparing the effects of strong Burst Mode TENS and High Rate TENS on painful osteoarthritis knees. Australian Journal of Physiotherapy 1992; 38(1): 49-56.

13. Jette DU. Effect of different forms of TENS on experimental pain. Physical Therapy.1986; 66: 187-192.

14. Randall L. Braddom, The Physiatric History and Physical Examination, Physical Medicine \& Rehabilitation, 3rdedition, Page- 7 .

15. E. C Huskisson- "Measurement Of Pain"-The Lancet. 1974; 304(7889): 1127-31

16. R. Marks. Reliability and Validity of Self-Paced Walking Time Measures for Knee Osteoarthritis. Arthritis Care and Research. 1994; 7(1):50-3

17. J J Cipriano. Photographic manual of regional orthopaedic and neurological tests. $5^{\text {th }}$ edition. Lippincott, Williams and Wilkins. Philadelphia. 2010: 5

18. Firat Altay, Dilek Durmus, Ferhan Cantürk. Effects of TENS on Pain, Disabiliy, Quality of Life and Depression in Patients with Knee Osteoarthritis. Turk J Rheumatol 2010; 25: 116-21.

19. Atamaz FC, Durmaz B, Baydar M, Demircioglu OY, Iyiyapici A, Kuran B, Oncel S, Sendur OF. Comparison of the efficacy of transcutaneous electrical nerve stimulation, interferential currents, and shortwave diathermy in knee osteoarthritis: a double-blind, randomized, controlled, multicenter study. Arch Phys Med Rehabil 2012; 93:748-56.

20. Pearl P.W. Law and Gladys L. Y. Cheing, Optimal Stimulation Frequency Of Transcutaneous Electrical Nerve Stimulation On People With Knee OA. Journal of Rehabilitation Medicine 2004; 36: 220-225. 